\title{
A Price Index Model for Road Freight Transportation and Its Empirical analysis in China
}

\author{
Zhishuo Liu", Kuan Zhao, Jingmiao Ma and Chunfang Wang \\ School of Traffic and Transportation, Beijing Jiaotong University, Beijing ,China
}

\begin{abstract}
The aim of price index for road freight transportation (RFT) is to reflect the changes of price in the road transport market. Firstly, a price index model for RFT based on the sample data from Alibaba logistics platform is built. This model is a three levels index system including total index, classification index and individual index and the Laspeyres method is applied to calculate these indices. Finally, an empirical analysis of the price index for RFT market in Zhejiang Province is performed. In order to demonstrate the correctness and validity of the exponential model, a comparative analysis with port throughput and PMI index is carried out.
\end{abstract}

Keywords. Logistics, road freight transportation, price indices, Laspeyres method.

\section{Introduction}

The road transport industry is often low running and "market failure" condition often appears because the road transport market price, cost, supply and demand information are not transparent and asymmetric. At the same time, transport enterprises have insufficient grasp of the market. The dynamic indices and general indices are so less that they can't meet the needs of industry analysis and decision making. As a result, the information used to reflect the climate condition of the transport market is inadequate and lack of quantitative analysis. So a quantitative indicators to evaluate prices and the condition of the transport market are needed urgently. The price index for RFT can comprehensively reflect the transport price, costs, climate information of shipping business. They can also reflect the situation of the road transport market, forecast industry trends and provide strong evidence for government and corporate decision. Firstly, a price index model for RFT based on the data from Alibaba logistics platform was built. Then the road transport market in Zhejiang Province was selected to make an empirical analysis, and the results show that this model can reflect the market situation perfectly.

\section{The research status of road transport price index}

Scholars have studied the Price Index for RFT in research methods. Hanchao Guo et al. [1] made a price index system using weighted average index method and geometry average method based on Beijing freight market by gathering point time price information. Gu Jingyan et al. [2] analyzed the market for RFT in Yiwu as an example using the Fisher index method. Bin Liu et al. [3] constructed a four levels index system for the transport market in Ningbo by the arithmetic mean method. Guangcong Yan et al. [4] analyzed a transport market of a city which belongs to a pilot project launched by the government. They used the weighted average method for index to work out the indices after gathering data from the sample enterprises and transport routes. 
As for the application status of price index methods, there are some price indices for freight transport at home and abroad. At the aspect of shipping price indices, Baltic Exchange issued the Baltic dry freight index(BFI) [5] for the worldwide dry bulk shipping market in 1985.The index system revealed the supply and demand for dry bulk shipping market and related markets such as shipbuilding market. In 1998, China's export Container Freight Index (CCFI) [6] issued by the Shanghai Shipping Exchange for existent several liner for container transport market. They used the Laspeyres [7] method to calculate the indices so as to reflect comprehensive indicators of China's export container transportation market prices. In terms of price indices for RFT, in July 2006, China Federation of Logistics \& Purchasing (CFLP) and Best Express jointly issued a national general cargo freight index [8] based on the data of medium-sized and small enterprises. It was used to reflect the changes of supply and demand of road transport market. In June 2015, CLFP and a Logistics enterprise called Linan jointly issued Highway Price index (HPI) [9]. The index was based on the dynamic transaction information which came from logistics platform of road represented by the Linan logistics network. Although the data is true and reliable, it belonged to the single enterprise and was not comprehensive. In 2012, Zhejiang Provincial Communication Department and local government jointly released of price index for RFT for Yiwu [10]. It was used to reflect Yiwu area and the Zhejiang Province of road transport market based on different routes which start from Yiwu and ended in other cities. In June 2015, Ministry of Transport of the People's Republic of China (MOT) released of China Freight Price Index (CFI) [11]. The data came from a pilot work results which belonged to a project carried out by MOT. Although the data covered a wide range, the authenticity, reliability and sustainability of this data needed to be tested.

It can be seen from the above analysis that methods of constructing a price index for road become more and more mature. As for the construction of the index system, the reliability of data representation and the data sources are deficiency. So this paper build a three levels index system including total index, classification index and individual index. This indices divide the index system from multiple dimensions according to the practical situation. In this way, the difficulty of data collection can be reduced and the project will be launched easily.

\section{The price index model for RFT}

\subsection{Selecting the method of price index of RFT}

Laspeyres index method and Paasche index method are widely used in practice because they are simple, practical. Although the results of the two methods can indicate the degree of the change in indices, there are some differences between them in terms of the economic significance. As for price of freight transport index, Laspeyres index method can indicate the change of price and the impact on total transportation cost based on the transport volume during the base period. And Paasche index method is based on the transport volume during the report period. Therefore, both of them have real economic significance. Paasche index method based on the report is more realistic compared to Laspeyres index method. In order to reflect the impact to the change degree of price in different periods because of pure price change and the size of the calculated values, the Laspeyres index method is applied to calculate the indices. The calculation formula is as follows:

$$
I_{t}=\frac{\sum q_{0} p_{t}}{\sum q_{0} p_{0}} \times I_{0}
$$

$p_{0}$-the transport price during the base period. $p_{t}$-the transport price during the report period. $q_{0}$-transport volume during the base period $I_{0}$-the transport price during the base period $I_{t}$-the transport price during the report period

\subsection{Designing the transport price index system}

Considered the actual situation and data acquisition, the transport price index system was built including total index, classification index and individual index as shown in Figure 1.Total index refers to index for RFT. Individual index refers to the route of transport. Classification index refers to the index which divided by departure place, mileage, the way of organizing goods, the type of goods, speed, calculating period and the choice of base period. 


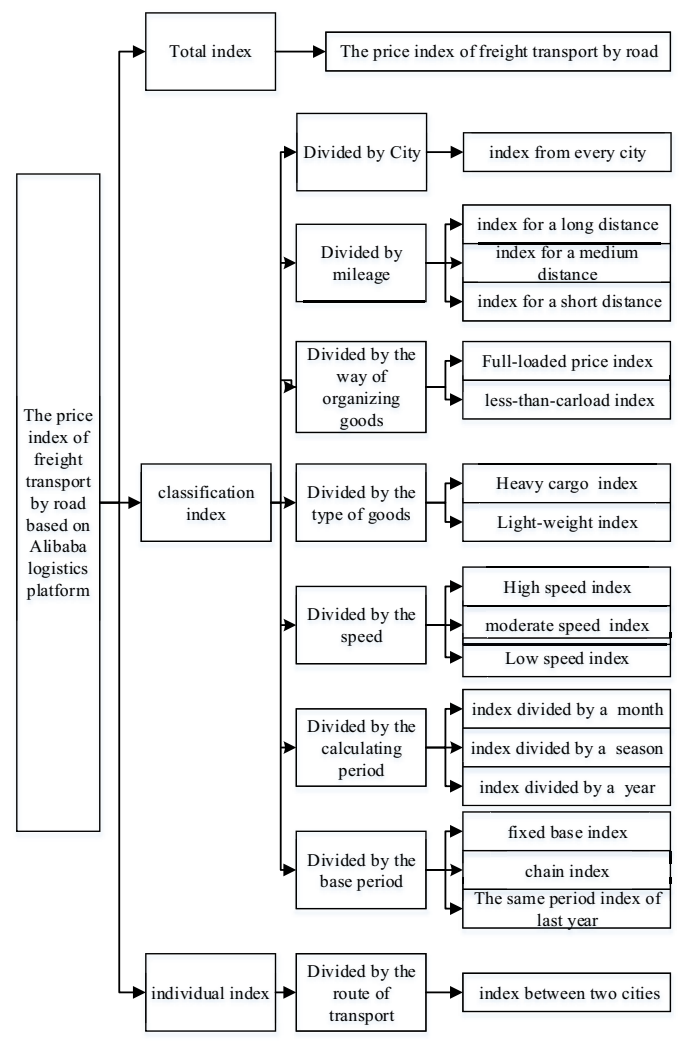

Fig. 1. The transport price index system.

\subsection{Calculating the transport price index}

According to the road transport price index system, the formulas of calculating indices at various levels are as follows.

\subsubsection{The calculation formula of individual index}

The individual index is divided by the routes of transport when the transport price and volume from logistics enterprises are taken into consideration. Supposed that the amount of logistics enterprises is $\mathrm{M}$ on each route, the formula is as follows.

$$
I_{1}^{t}=\frac{\sum_{i=1}^{i=M} p_{1}(i) q_{0}(i)}{\sum_{i=1}^{i=M} p_{0}(i) q_{0}(i)} \times I_{0}^{t}
$$

As in (2), $I_{1}^{t}$ represents the transport price index on the $t$ line during report period and $I_{0}^{t}$ represents the index during the base period. $p_{0}(i)$ represents the transport price from the I logistics enterprise during report period and $p_{1}(i)$ represents the price during the base period. $q_{0}(i)$ represents the transport volume from the I logistics enterprise during the base period.

\subsubsection{The calculation formula of classification index}

Firstly, the index is divided by different departure city and an example of the transport price index from $\mathrm{t}$ city is taken. Supposed that the amount of routes departing from $\mathrm{k}$ city is $\mathrm{N}$ and there are $\mathrm{M}$ logistics enterprises on each route, the formula is as follows. 


$$
I_{1}^{k}=\frac{\sum_{j=1}^{j=N} \sum_{i=1}^{i=M} p_{1}(i j) q_{0}(i j)}{\sum_{j=1}^{j=N} \sum_{i=1}^{i=M} p_{0}(i j) q_{0}(i j)} \times I_{0}^{k}
$$

As in (3), $I_{1}^{k}$ represents the transport price index for the $\mathrm{k}$ city during the report period and $I_{0}^{k}$ represents the index during the base period. $p_{0}(i j)$ represents the transport price from the I logistics enterprise on the route $\mathrm{j}$ during the base period and $p_{1}(i j)$ represents the price during the report period. $q_{0}(i j)$ represents the transport volume from the I logistics enterprise on the route $\mathrm{j}$ during the base period.

Then the index is divided by transport mileage, including long-distance index, medium distance index and short distance index. Supposed that there are K departures with N routes and each route has M logistics enterprises, the formula is as follows.

$$
I_{1}^{l}=\frac{\sum_{k=1}^{k=K} \sum_{j=1}^{j=N} \sum_{i=1}^{i=M} p_{1}(i j k) q_{0}(i j k)}{\sum_{k=1}^{k=K} \sum_{j=1}^{j=N} \sum_{i=1}^{i=M} p_{1}(i j k) q_{0}(i j k)} \times I_{0}^{l}
$$

As in (4), $I_{1}^{l}$ represents the transport price index for the 1 kinds of mileage during the report period and $I_{0}^{l}$ represents the index during the base period. $p_{0}(i j k)$ represents the transport price for the $\mathrm{i}$ logistics enterprise on route $\mathrm{j}$ departing from city $\mathrm{k}$ during the base period. $p_{1}(i j k)$ represents the price during the report period.

Next, the index is divided by types of organizing transport, including full-loaded index and less-than-carload index. Supposed that there are k departure city with $\mathrm{N}$ routes and each route has M logistics enterprise, the formula is as follows.

$$
I_{1}^{r}=\frac{\sum_{k=1}^{k=K} \sum_{j=1}^{j=N} \sum_{i=1}^{i=M} p_{1}(i j k) q_{0}(i j k)}{\sum_{k=1}^{k=K} \sum_{j=1}^{j=N} \sum_{i=1}^{i=M} p_{1}(i j k) q_{0}(i j k)} \times I_{0}^{r}
$$

As in (5), $I_{1}^{r}$ represents the transport price index by the $\mathrm{r}$ type of organizing transport during the report period and $I_{0}^{r}$ represents the index during the base period. The meaning of other variables are the same as mentioned above.

Next, the index is divided by the type of goods including heavy cargo index and light-weight index. The formula is as follows.

$$
I_{1}^{S}=\frac{\sum_{k=1}^{k=K} \sum_{j=1}^{j=N} \sum_{i=1}^{i=M} p_{1}(i j k) q_{0}(i j k)}{\sum_{k=1}^{k=K} \sum_{j=1}^{j=N} \sum_{i=1}^{i=M} p_{1}(i j k) q_{0}(i j k)} \times I_{0}^{S}
$$

As in (6), $I_{1}^{S}$ represents the transport price index for the s type of goods during the report period and $I_{0}^{S}$ represents the index during the base period. The meaning of other variables are the same as mentioned above.

Finally, the index is divided by transport speed including the high speed index, moderate speed index and low speed index. The formula is as follows.

$$
I_{1}^{u}=\frac{\sum_{k=1}^{k=K} \sum_{j=1}^{j=N} \sum_{i=1}^{i=M} p_{1}(i j k) q_{0}(i j k)}{\sum_{k=1}^{k=K} \sum_{j=1}^{j=N} \sum_{i=1}^{i=M} p_{1}(i j k) q_{0}(i j k)} \times I_{0}^{u}
$$

As in (7), $I_{1}^{u}$ represents the transport price index at the u kind of speed during the report period and $I_{0}^{u}$ represents the index at the $u$ kind of speed during the base period. The meaning of other variables are the same as mentioned above.

\subsubsection{The calculation formula of complex index}

The complex index consist of different classification indices. For example, the transport price index of full-loaded for a city involves two classification indices: the index divided by city and the index divided by the type of goods.

\subsubsection{The calculation formula of total index}

Although there are kinds of formula for total index, they originate from Laspeyres method, the formula to calculate the total index is designed according to the city, the mileage, the types of organizing transport, the types of goods and transport speed. Supposed that the amount of cities is $\mathrm{K}$ and the city $\mathrm{k}$ has $\mathrm{r}$ kinds of types of organizing transport. At the same time, there are s kinds of goods in each types of organizing transport. Then there are $u$ kinds of speed in $s$ kinds of goods. There are $\mathrm{N}$ routes in the $\mathrm{u}$ kinds of speed when the amount of logistics enterprise is $\mathrm{M}$ in the route $\mathrm{n}$. So the formula is as follows. 


$$
I_{1}=\frac{\sum_{k=1}^{K} \Sigma_{r=1}^{R} \sum_{s=1}^{S} \Sigma_{u=1}^{U} \sum_{j=1}^{N} \sum_{i=1}^{M} p_{1}(i j u s r k) q_{0}(i j u s r k)}{\sum_{k=1}^{K} \sum_{r=1}^{R} \sum_{s=1}^{S} \Sigma_{u=1}^{U} \sum_{j=1}^{N} \Sigma_{i=1}^{M} p_{0}(i j u s r k) q_{0}(i j u s r k)} \times I_{0}
$$

As in (8), $I_{1}$ represents the total transport price index during the report period and $I_{0}$ represents the index during the base period.

Generally, each transport price index value during the base period is set to 100 .

\section{Price index for RFT complied instance}

\subsection{Selecting RFT samples}

The first step to compile the transport price index is to determine the sample. There are some principles should be followed such as typical principle, the relevant principles and information accessible principles. So the sample routes must occupy numerous market share. At the same time, it can indicate the change degree of the total transport price through its change. According to the principles mentioned above, the sample routes is selected which start from Zhejiang province and end in other cities based on the Alibaba logistics planform.

\subsection{Data source and processing}

The transport price data and transport volume data have been got from the Alibaba logistics platform using data capture technology. These raw data include the name of the 11 departure cities and destination cities, the name of logistics enterprises, weight of goods, transport mileage, transport time and speed.

Meanwhile, there are some missing values and outliers needed to be processed at first. First of all, the method of using data capture technology to get the data may lead to miss some information such as route and the weight of freight. So a step to simulate the missing data for the route is necessary according the history data and a nearby transport route. Next, there are outliers in raw data. An average value of the data can be used to replace the outlier.

\subsection{Statistics and analysis}

The data is input and the index is calculated according to the data collected. The excel table consists of date, provinces, departure, destination, logistics enterprises, the price of heavy and light-weight goods, weight, volume, the full-loaded price, the number of vehicles, transport time, mode of transport and the type of goods.

\subsubsection{The total index for RFT}

In this paper, the fixed base index is taken as an example. The index curve are drawn from September 2015 to August 2016 according the road transport price index model mentioned above. This indices include total index, classification index and individual index, as shown in Figure 2 to Figure 4.

In order to analyze the fluctuation of the total index for RFT, the correlation between the port cargo throughput and the total index for RFT in Zhejiang is examined by using bivariate similarity theory. The results of the analysis are shown in Table 1.

Table 1.Correlation test.

\begin{tabular}{|c|l|c|c|c|}
\hline \multicolumn{5}{|c|}{ Correlation coefficient } \\
\hline \multicolumn{2}{|c|}{} & $\begin{array}{l}\text { Throu- } \\
\text { ghput }\end{array}$ & $\begin{array}{c}\text { Total } \\
\text { index }\end{array}$ \\
\hline $\begin{array}{l}\text { Spearm } \\
\text { an's rho }\end{array}$ & $\begin{array}{l}\text { Throughp } \\
\text { ut }\end{array}$ & CC & 1.000 & .721 \\
\cline { 2 - 5 } & Sig &. & .000 \\
\hline
\end{tabular}




\begin{tabular}{|l|l|l|r|r|}
\hline \multirow{4}{*}{$\begin{array}{l}\text { Total } \\
\text { index }\end{array}$} & $\mathrm{N}$ & 41 & 41 \\
\cline { 2 - 5 } & $\mathrm{CC}$ & .721 & 1.000 \\
\cline { 2 - 5 } & $\mathrm{Sig}$ & .000 &. \\
\cline { 2 - 5 } & $\mathrm{N}$ & 41 & 41 \\
\hline
\end{tabular}

From the correlation result, it can be seen that the original hypothesis that the two variables are uncorrelated should be denied according to the Confidence $\mathrm{Sig}=0<0.05$. And the correlation coefficient is equal to 0.721 . From the result of above analysis, the port cargo throughout has an effect on the price index for RFT in Zhejiang and this result can gave us an evidence to compare the two variables. At the same time, the total index for RFT is compared with PMI index which can reflect the trend of microeconomic development. In this way, the reason for the index fluctuation will be found. The results are shown inFigure 2 .

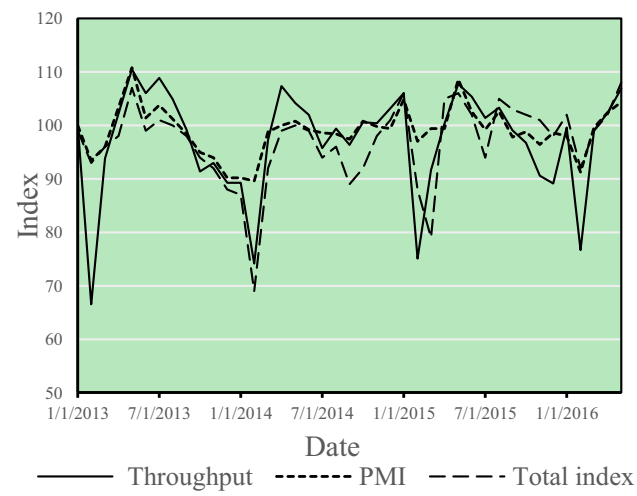

Fig.2. The total price index for RFT in Zhejiang.

From Figure 2, the changing trends of the three line graphs are basically the same. When compared to the port throughput in Zhejiang, the total index for RFT is declining form April 2013 to January 2014. And the freight volume for input and output is decreasing in Zhejiang province, which means the decline of shipping volume will have a negative effect on the market for RFT. From July 2014 to January 2015, both of them are rising. This result means that if the shipping volume become larger, the transport price should be higher and the market for RFT should be boom. When compared to PMI index, the total index also shows a slight downward trend but not obvious. It was significantly decreased until April 2014, which is caused by the lag of linkage response. From July 2014 to January 2015, both of them are rising. During this period, the microeconomic has developed well. There are export-oriented economy and strong export in Zhejiang province. So, the demand for RFT is larger and the market is more active.

\subsubsection{The classification index for RFT}

In this paper, the freight volume from Zhoushan port is taken as an example. The relationship between port throughput in Zhoushan and the individual index is analyzed. The results are shown in Figure 3. 


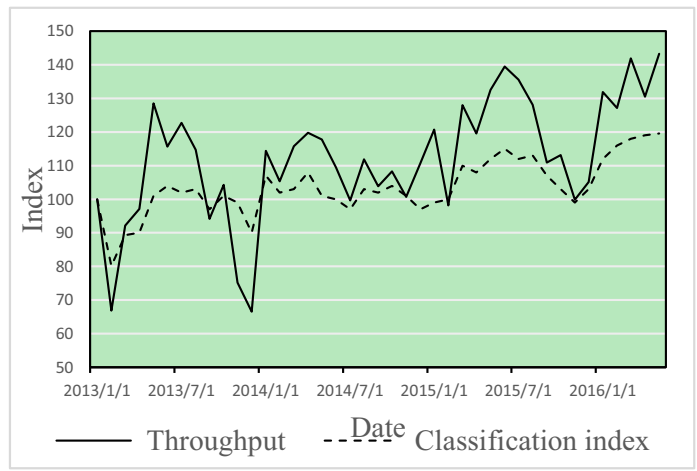

Fig.3. The classification price index divided by city.

From Figure 3, it can be seen that the overall trend of the two curves is upward from January 2013 to May 2016. And they fluctuate in the same way. For example, from January 2015 to July 2015, the cargo throughput of Zhoushan port increased, which indicated the demand of shipping freight was bigger. When using the road way and water way to import and export, the road freight traffic volume rises. Then the road freight market is more active and its trading volume is larger. Then it can be seen that the trend of the freight index is consistent with the freight throughput.

\subsubsection{The individual index for RFT}

In this paper, the Ningbo-Beijing highway freight line is taken as an example. The date of October 2013 is set as the base month and the index is compared to the National Road Freight Price Index (CFI) from October 2013 to May 2016. The results are shown in Figure 4.

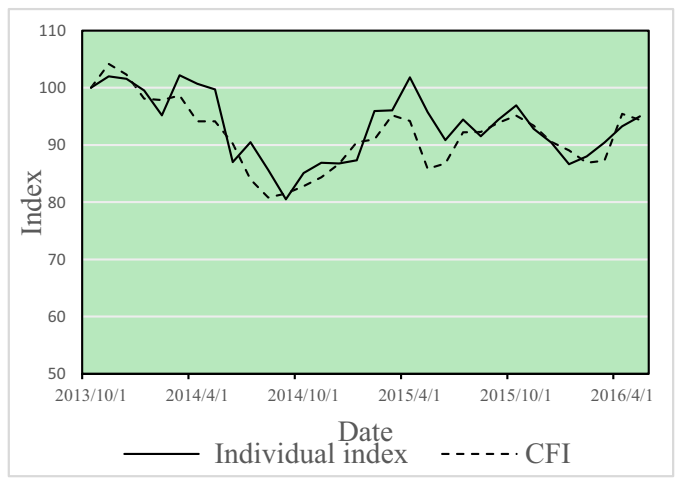

Fig.4. The individual price index divided by route.

From Figure 4, it can be seen that the change trend of the branch line index is consistent with the overall change trend of the CFI index. This indicates that both of the two indexes can reflect the road freight market prosperity of the Ningbo Beijing line.

\section{Conclusion and discussion}

In this paper, the background, existing problems and research significance of Chinese road transport are described firstly. Then some typical domestic and foreign price indices are summarized. Next, the Price Index model of Road Freight Transport based on the Alibaba logistics platform is built. At the same time, an empirical analysis is performed by using the Laspeyres index method after designing the way for collecting data. Finally, the corresponding index curves are drawn 
according to the indices. By analyzing and comparing the results to PMI index and port throughput, it turns out that the index can well reflect the demand and trading situations of transport market.

This paper puts the transport price index research into practice, and it's also an improvement of transport index system. At the same time, it will contribute to the investment and management decisions-making of freight industry subjects; it's conductive to optimize resource allocation of transport market and improve the freight industry training mechanism; and it could help the industry supervision authorities to monitor the operations of market and enhance their service capability.

\section{Acknowledgement}

The research is supported by National Science and Technology Support Program Grant No.2014BAH24F02.

\section{References}

1. H.C. Guo, L.M. Sun, BJ.Fif.S.S.C, pp.7 (2009).

2. J.Y. Gu, W.J. Fan, TST, 09:154-158(2013).

3. B. Liu, G.Y. Jiang, J.D. Chen, NBU.J, 03(2015).

4. G.C. Yan, H.D. Nie, G.Q. Shi, R\&M, 05:62-64(2015).

5. X.R. Cai, CA.Tra.Sci, 04(2012).

6. L.J. Chen, S.Q. Yu, Chi.Wat, 02:12-13(2004).

7. G.X. Xv, China Statistics Press, 11-12(2004).

8. Y.B Ma, Int.Tra, 09:69-72(2007).

9. J.Y. Li, C.Sto\&Tra, 08:72-73(2015) .

10. W.G. Zhao, H. Wang, Y. Zhong, TST, 02 (2012).

11. J. Qi, Tran.Man.Wor, 07:50-51(2015). 